\title{
Leveraging management information in improving call centre productivity
}

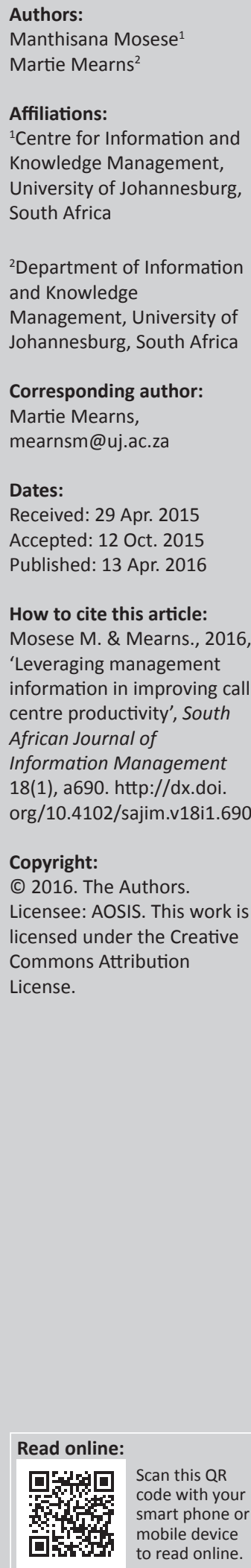

Background: The availability and efficient use of management information is one of the key strategic levers in driving growth and competitiveness for companies. Management information facilitates vital decision making that assists organisations in improving their competitiveness. For call centre operations, competitiveness entails improving productivity and customer service, and management information is essential in this endeavour.

Objectives: This research explored the use of management information and its impact on two fundamental functions namely, improving productivity without compromising the quality of service, in the call centre of a well-known South African fashion retailer, Edcon. Following the implementation of the call centre technology project the research set out to determine how Edcon can transform their call centre to improve productivity and customer service through effective utilisation of their management information.

Method: Internal documents and reports were analysed to provide the basis of evaluation between the measures of productivity prior to and post the implementation of a technology project at Edcon's call centre. Semi-structured in-depth and group interviews were conducted to establish the importance and use of management information in improving productivity and customer service.

Results: The results indicated that the availability of management information has indeed contributed to improved efficiency at the Edcon call centre. Although literature claims that there is a correlation between a call centre technology upgrade and improvement in performance, evident in the return on investment being realised within a year or two of implementation, it fell beyond the scope of this study to investigate the return on investment for Edcon's call centre.

Conclusion: Although Edcon has begun realising benefits in improved productivity in their call centre from their available management information, information will continue to play a crucial role in supporting management with informed decisions that will improve the call centre operations.

\section{Introduction}

The impetus for improving the performance of a company is motivated by the highly competitive and globalized industry in which the company operates. For many organisations, it has become increasingly challenging to stay competitive merely from products and conventional face-to-face services (Du Preez 2008:1). The provision of additional facilities and functional areas that supplement products and services have thus become important competitive differentiators for companies. Call centres are one of the facilities deemed crucial to competitive differentiation (Barnett 2006) and they are the subject of this article.

Call centres have developed into effective means of improving service quality, promoting product offerings, and communicating with current and prospective customers (Du Preez 2008:2; Banks \& Roodt 2011:1; Barnett 2006). Consequently, call centres have become a vehicle for improving the performance of organisations. They serve a critical role as they may function as the primary, and possibly the only point of contact between an organisation and its customers (Aksin, Armony \& Mehrotra 2007:665). A call centre is defined as a 'place where most crucial customer interactions take place' (Reynolds 2010:3). Rademeyer (2012:7) supplements the above definition by referring to a call centre as a 'one stop shop for sales or for product information and services or for customer service'.

As with many other business processes and functions, call centre operations have become computerised and are often considered a source of testing new information technologies (IT) 
(Rowe, Marciniak \& Clergeau 2010:337). Call centre IT and systems have evolved into sophisticated devices offering features such as predictive dialling, and intelligent, dynamic routing of calls based on agent skills and knowledge (Robinson \& Morley 2006:28). These mechanisations have enabled effortless access to information collected through the interaction with customers and with other systems. Despite the mentioned technological edge, the ability on the part of many enterprises to fully exploit information is still developing (Brooke 2002:393). In his 2003 study, Sharp (2003) reported that workforce management systems (WFM) as one of call centre management information systems (MIS) are used in only $10 \%$ of call centres. A more recent study, as found in a 2011 report by DMG Consulting, indicates an improvement in the use of call centre MIS, however, 'the adoption rate of WFM is still surprisingly low' (DMG Consulting 2011:1) for larger call centres. Optimal usage of existing information within the MIS to improve productivity and customer service still remains a challenge for many organisations (Prunty \& Pritchard 2006:3) and Edcon was one such enterprise.

Edcon is the largest clothing, footwear, and textiles retailer in Southern Africa with approximately 20000 employees and more than 1400 stores in South Africa, Botswana, Namibia, Swaziland, Lesotho, Mozambique, Ghana, and Zambia. The Edcon call centre is part of the Edcon Credit and Financial Services (CFS) Division. Edcon is a registered financial services provider and acquired this status in 2007. The call centre was, however, established in 1997 and at the time the focus of the call centre was on credit collections and customer services only. In 2008 its services expanded to offering fullfledged financial services in the form of banking, insurance services and other value-adding services such as the ability to pay for services using the Edcon private label store card. The Edcon call centre employs approximately 1,100 employees and is comprised of outbound and inbound operations. The outbound operations manage collections and on occasion, new business in the form of new accounts, whilst the inbound operations involve customer service and also new business.

In order to improve efficiency amidst the highly competitive and volatile retail industry, the Edcon CFS was compelled to consolidate their different call centre environments, whilst investigating means of acquiring and effectively using management information (MI) to optimise their operations (Edcon RFP 2011). It was through the implementation of a technology project, the CC Project, that new technology in the form of WFM, integrated Interactive Voice Recorder (IVR), Credit Management System (CMS), and comprehensive quality management that enabled the call centre to acquire new MI and enhance their measures of customer service and productivity. For Edcon, productivity is expressed through the number of calls the agents handle per day based on the number of hours worked, call abandon rates, service levels, and talk time. For collections, it is also based on the number and the value of local currency (ZAR for South Africa, Pula for Botswana etc.) collected per agent. The number of calls has to be delicately balanced against effectiveness as agents can handle many short calls without resolving customer's queries or collecting revenue.

With this background in mind, this article argues that through availability and effective use of information, Edcon was able to transform their call centre by improving productivity and customer service. This claim is informed by the research, which aimed to satisfy the following research question:

Following the implementation of the call centre technology project (CC project), how can Edcon transform their call centre to improve productivity and customer service through effective utilisation of their management information?

Although the subject of call centres has been extensively studied, the focus has generally been on the performance of call centres and the issues relating to improving the performance of call centre agents. Limited research has specifically studied and linked MI to improved productivity and customer services although Belfiore, Chatterley and Petouhoff (2012:7) have found evidence that advanced call centre technology improves call centre performance and customer service. Edcon defines customer service through the following important measures: the speed of answer, first time resolution, call abandon rates, and customer satisfaction. Although first time resolution is an important measure, there is no scientific tool to measure this as it is subjective and the views of the agent and the customer may differ. Edcon does, however, use these predefined statistics to measure customer service:

- $70 \%$ of applications completed in 60 minutes

- $95 \%$ of applications completed in 24 hours

- $97 \%$ of applications completed within 10 business days

- $75 \%$ of calls answered within 20 seconds

- $3 \%$ abandon rate

- Complaints

- $70 \%$ (responded in 48 hours)

- $95 \%$ (responded in 5 business days)

Rowe et al. (2010:337), however, validate the view that there is a lack of association between IT and call centre productivity. This article therefore seeks to demonstrate that the use of MI contributes to improving call centre performance.

The article firstly examines the subject of MI within a call centre environment, and reviews perspectives and principles relating to the concepts of customer service and productivity in general, and within the Edcon call centre.

\section{The management information concept}

The meaning of MI can be inferred from defining and understanding the concepts of information and MIS.

Information is said to be one of the strategic and critical assets of any organisation (Higson \& Waltho 2010:2). As AdeotiAdekeye (1997:318) highlights, information is power and 
whoever possesses information possesses power. In the information and knowledge management sphere, information forms the building blocks to informed decision making and it is defined as data made meaningful and used for decision making. Citing a 1985 Davis and Olson definition of information, Zins (2007:480) defines this term as 'data that has been processed into a form that is meaningful to the recipient'. It is a result of organising data to respond to the questions of what, who, when, and where. Another interesting interpretation of this term as per Zins (2007:483) is that information is data that is meaningful, communicated, has objectives and consequences, and allows coherent decisions.

Given the significance of information in companies, the management of information likewise becomes a vital function that ensures that the right information is available at the right time for use in decision making (Adeoti-Adekeye 1997:320). In this regard, technology has played a valuable enabler with the development of information systems. An information system is a computer system wherein data is recorded and processed to produce information (Giao, Borini \& De Miranda Oliveira 2010:336). A MIS is thus an information system that supplies management - at different managerial levels - in an organisation with relevant information required for informed decision making (Mahesh 2010:11).

Having defined the concepts of information and MIS, MI can thus be surmised as information that is derived from MIS, and that is disseminated to managers at different managerial levels to assist them in decision making. According to McCrae et al. (2012:27), MI includes financial, operational, performance, productivity and risks information, which is refined through continuous use and will often inspire insight and questions into the performance of an organisation. As an instrument for informed decision making, MI has been used by management in companies for many years to make critical decisions that benefit their organisations (Barzegar, Araghieh \& Asgarani 2012:192). It is one of the indispensable tools used for effective decision making. MI provides a holistic view of all information and is thus an essential requirement in meeting the goals of improving customer service and increasing productivity. Dimension Data's 2013-2014 global contact centre benchmarking report affirms that MI has assisted call centre executives and provides evidence (in the form of transformations in performance) that the implementation, upgrade, or transformation of their company call centre has yielded benefits (Dimension Data 2014).

\section{Management information in a call centre}

In a call centre, MI can be extracted from a number of MIS including but not limited to the following aspects:

- Workforce Management (WFM) is a system that uses historical data to forecast the number of calls that can be expected in the future, and thus enables call centre management to schedule agents accordingly. Information relating to schedule efficiency, staff occupancy, and adherence to schedule are available to management for quick and effective decision making (Reynolds 2010:5). Without WFM, call centre managers are confronted with having to balance the right amount of staff, with the right skills for the workload expected, whilst delivering on improved productivity and quality service.

- Interactive Voice Recorder (IVR) is a tool that provides automatic menus to call centre customers. It is used to encourage customer self-service or to direct the call to the correct agent as directed by the menu options. Information available from the IVR includes the use of menus and the exit points (Reynolds 2010:5).

- Customer communications recording allows for all calls entering the call centre to be recorded. The recordings are used to drive the improvement and quality of service provided by the call centre. Typically, a random number of calls are selected for auditing, and decisions on the improvement of service made (Reynolds 2010:5).

- Customer relationship management (CRM) is regarded as a crucial instrument in improving customer service management. According to Holman, Batt and Holgrewe (2007:31), skills-based routing is thought to be effective relationship management in a call centre. This is debatable as the same authors also indicate that call centre employees need to be well trained and skilled in order to provide quality customer service (Holman et al. 2007:31). It is important to have a CRM strategy along with well-skilled employees to increase call centre productivity (Holman et al. 2007:31).

- Credit and Management System (CMS) is a system in which customer information such as credit history, buying patterns, payment records and a wide variety of customer demographic and behavioural information are stored and used to draw insight into customer buying patterns, preferences, payment methods, and the store they visit mostly (Holman et al. 2007:31).

The above provide a view of a few of the information systems available in a typical call centre. According to Barzegar et al. (2012:191), productivity and customer service are closely linked with access to relevant information and the efficient use of that information. As such, the right information at the right time plays a significant role in improving productivity and customer service.

\section{Call centre productivity concept and measures}

Call centres usually measure customer service and productivity by using predefined statistical modelling. This is done through operational data in inputs such as service durations, abandon rates, call arrival rates, and many others (Belfiore et al. 2012:7; Marr \& Neely 2004:5; Shen \& Huang 2008:252). A survey conducted by Knowlagent Productivity Plus (2011), illustrates that increasing productivity was ranked as a priority challenge for call centre executives.

Productivity is defined as the 'measurement of the amount of work accomplished during a specified time frame'; in a call 
centre environment it would be reflective of the number of customers that can be serviced over a specific time (OECD, n.d.). Rowe et al. (2010:341) refer to productivity as a quantitative aspect of a call centre, which deals with measures such as, but not limited to:

- the number of calls waiting versus the proportion of calls answered

- the average call duration

- the customer waiting time

- the number of agents on a call at a given period

- abandonment rate (outbound calls).

Gupta et al. (2008:2) suggest that it is necessary to include other factors to improve productivity over and above quantifiable measures. These factors should include: a full picture of information pertaining to customers' profiles, a process that will exploit this customer information, and information on call centre agents' skills required to perform at an optimal level. Marr and Neely (2004:5) endorse this statement by alleging that the employee characteristics that create value for companies and their customers have been largely ignored in favour of quantitative statistics that measure productivity. They argue that quantitative productivity measures alone have shown to be counterproductive to achieving customer satisfaction and that the performance of the call centre as a whole is integral to improved customer service.

\section{Call centre customer service concept and measures}

Customer service is the total value of what an organisation does to meet and sometime exceed customer's expectations (Edwards 2009:13). Customer service measures typically revolve around the duration the customer must wait to receive value or quality service from their interaction with the service provider (Aksin et al. 2007:666). Customer service measures typically include:

- average speed of answer

- first time resolution

- abandonment rate (inbound calls)

- average talk time

- adherence to schedule.

First time resolution is recognised as the most important customer service measure in a call centre, however, it is found to be the most challenging to measure as it involves customer's perspectives and expectations (Stringham \& Cotter 2012:2). Customer satisfaction surveys can be used to offset the challenges of measuring first time resolution and are recorded in Marr and Neely's (2004) study as a key objective of a call centre. There seems to be consensus on the importance of surveys among researchers, however, the response rate is typically very low. This is according to an article by Vocal Laboratories (2014), which also reports the response rate of surveys as varying between just under $1 \%$ to over $60 \%$.

The measures of productivity and customer service are the basis of vital information that enables appropriate management of operations for call centre management. Based on the information these measures provide, a view of possible deviations and potential contrasts with global norms can be corrected. Important and informed decisions that may change the course of a call centre operation can thus be made.

\section{Research methods}

A combination of both qualitative and quantitative methods was used for the research.

\section{Sampling method}

Purposive sampling technique was utilised to select the sample for this research. This type of sampling was particularly suited for this research as the sample was small, limited to Edcon's CFS operation, and the researcher was deliberate in selecting the individuals to interview. These individuals were selected based on their seniority, knowledge, and the insights they possess necessary for this study. As Edcon's CFS call centre is divided into Collections and Services departments, the researcher took care to ensure representation from both operations. The sample was thus made up of the following:

- the executive of the CFS operations

- the head of collections department

- the head of services department

- two managers who oversee the collections and services operations

- eight call centre agents from both departments.

The sample was deliberately mixed as described to allow for balance and impartiality. The total sample for this research was 16 individuals and all relevant ethical clearances were negotiated with the research subjects and organisation.

\section{Data collection and processing methods}

The instruments used for collecting data for this research were both qualitative and quantitative. The qualitative data collections method was in the form of semi-structured faceto-face interviews for the individuals in management. The interviews were designed to capture the views and insights of the 16 interviewees pertaining to the current use of MI, the measures of customer service and productivity, and the opportunities and barriers to information access. Different interview questions, targeting the different levels of management were compiled. These questions were used to structure the interviews and to ensure that the scope of the interviews was adhered to, whilst allowing for flexibility to probe and vary the questions based on the direction the interview took. For call centre representatives, group interviews were conducted. The group interviews were also semi-structured and sought to gather different perspectives and views from employees at lower levels. With the permission of the interviewees, the interviews were audio recorded, and then transcribed before the process of analysis began. 
A portion of this research involved collecting and analysing historical data, which comprised data prior to the implementation of the CC project. This formed the quantitative portion of the data collected and productivity statistics were analysed from historical documentation over a certain period and then compared with data that was collected post the implementation of the CC project.

\section{Data analysis}

As a large amount of textual data was amassed from the semi-structured interviews, Atlas.ti, a computer-assisted qualitative data analysis software tool was utilised to analyse the interviews. For the quantitative data collected from historical information, Microsoft Excel was used to analyse and compare historical information and statistical norms gathered from the MIS that formed part of the call centre department, against the collected information following the implementation of phase one of the CC project.

\section{Research findings and discussion}

The findings and results of the research are presented below.

\section{Internal historical information findings}

The implementation of the CC project delivered additional MIS and thus the availability and accessibility of new and pertinent MI. Phase one of the CC project included, among others, the implementation of WFM, CRM, CMS integration, improved IVR, and quality assurance solutions. This phase covered the outbound collections department and was implemented in November 2013.

Productivity data on a month to month basis was plotted to show the differences in the measures prior and subsequent the implementation of the CC project. The statistics are comparable data for a period of 6 months in 2013-2014 with the same number of agents. The statistics relate to the collections department, and for the purpose of the article, only a sample of three measures are reported on.

Figure 1 presents a comparison in the number of accounts dialled prior and post the implementation of the CC project.

Figure 1 displays a significant increase in the number of calls being dialled post the implementation of the CC project for the same period. This signifies an increase in the number of successful connections the dialler made. Successful connections equates to improved productivity. The diagram shows tapering and then stability in the number of accounts dialled. This has been attributed to the dialler algorithms aligning to patterns and trends on the best time to call a customer and thus being successful in dialling the right numbers at the right time. The productivity of the agents is also improved as they are speaking to the right people at the right time, consequently increasing their promise-to-pay (PTP) rate.

Figure 2 presents statistics on the average number of dropped calls.

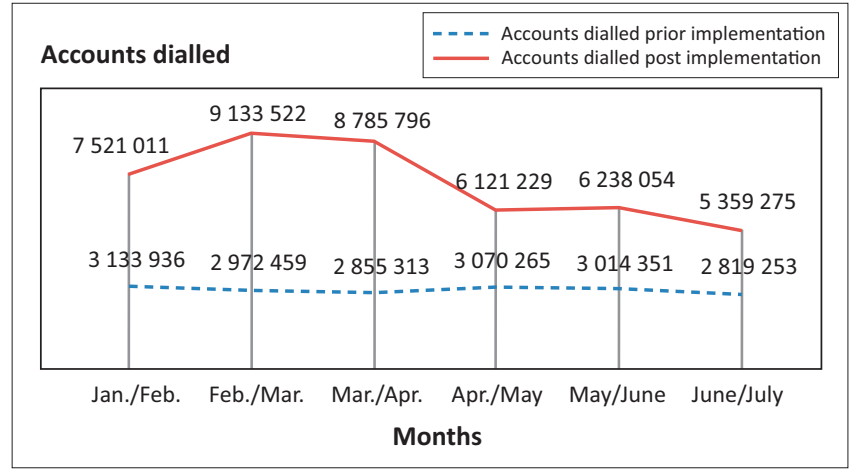

FIGURE 1: Number of accounts dialled.

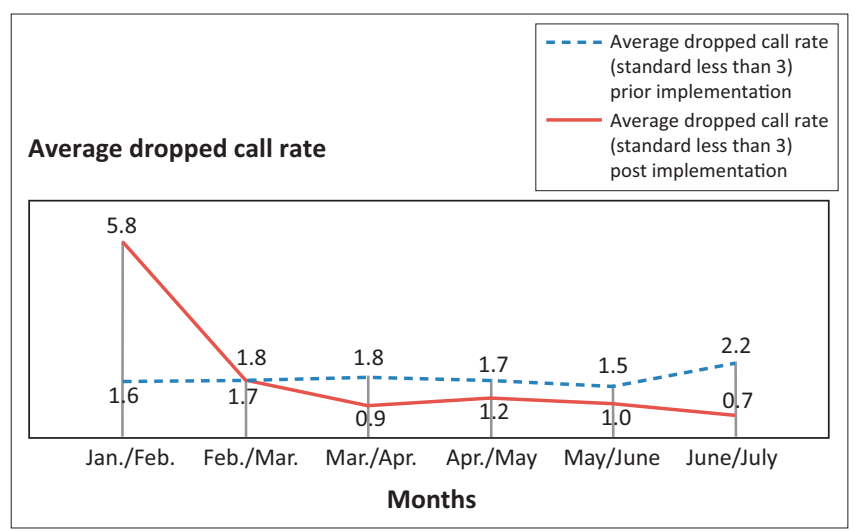

FIGURE 2: Average dropped call rate.

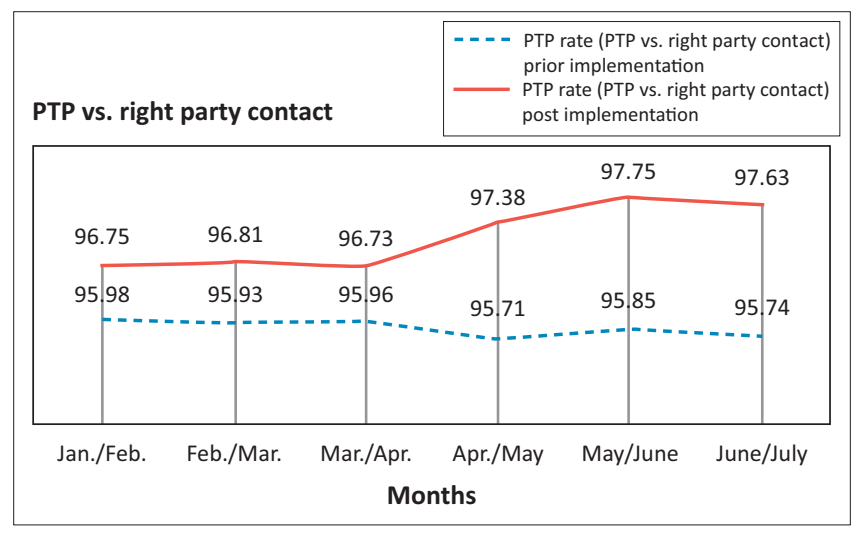

FIGURE 3: PTP versus account-holder contact.

From Figure 2, Edcon has had a steady and acceptable rate of abandoned calls, even prior to the implementation of the CC project. Post the implementation, the number of dropped calls was high and then decreased sharply in subsequent months. A low dropped call rate directly correlates to less calls being abandoned and the predictive dialler accurately connecting to the right customer at the right time. Best practice for the rate of dropped calls should be between 3\% and 8\% (International Finance Corporation 2015:3). At less than $1 \%$, the CFS is managing this measure exceptionally.

Figure 3 presents measurements on the number of PTPs against the actual account-holder.

The number of PTPs has also increased post the implementation of the CC project as depicted in Figure 3. 
Again, this can be credited to the efficiency of the predictive dialler in reaching the right account-holder. This is a clear measure of increased productivity for both the collections department and the agents.

In summary, from the above graphical comparisons of the productivity measures, the difference in productivity improvement for comparable months is distinctive. This is significant for Edcon as it shows that the implementation of the CC project is showing dividends. The agents are doing more work and they are producing results that are beneficial to, both themselves and to Edcon as a company. The new MI associated with the $\mathrm{CC}$ project will enable the management of the call centre plan better for the future.

\section{Group and in-depth interviews findings}

The transcribed interviews were coded and major themes comprising management information; measures; and challenges and opportunities were identified.

\section{Management information}

A number of questions relating to the role of MI in improving customer service and productivity and the effective use of MI for decision making were posed. Confidentiality is maintained using codes such as L1, L2 etc. for the participants of the interviews. For the CFS executive (L1), the role that MI plays in the CFS is crucial as it is an indicator of whether the call centre is living up to the service standards established. To L1, the call centre would not function without the necessary MI that they have daily to make decisions. This view matches the heads of services and collections departments (L2 and L3 respectively). For them MI is also crucial in identifying issues and then working towards a root cause. For lower level managers, phrases such as 'measurement of performance', 'drivers of performance', and 'assistance with staffing requirements' were referenced as crucial to them carrying out their daily tasks. There was consensus regarding the effective use of MI and all managers agreed this could improve.

The implementation of the CC project, and therefore the rollout of WFM and other MIS incited excitement and optimism among the entire management team. New information relating to volume forecasting, automatic scheduling and adherence to schedule seemed to have been much anticipated. The management all reported the cost and time savings, and the improvement in decision making the call centre has achieved (in collections) and will achieve (in services). According to L1, agent's adherence to schedule, as one of the customer service measures, improved from below $80 \%$ to $95 \%$ in collections since implementation. The International Finance Corporation's (IFC) global best practice guide lists the global metric at $95 \%$, bringing the collections department on par with global norms.

The management team reported that the priority for the CFS was to complete the implementation of the CC project to start realising the same benefits that collection is experiencing in services. They reported an expectation that the benefits the CFS has been able to realise so far will enable the growth of the operation. As a result, the management team have begun applying the MI they are receiving from the WFM in collections. They all understand that the ultimate goal for the call centre is to increase efficiencies and regain lost market share through creative offerings that the call centre can introduce. Increasing the IVR menu options were listed as a definite opportunity that is already underway.

The agents reported that availability and access to information improved their productivity. For them, the availability of their schedules online through WFM has been invaluable when they missed work for some reason or arrived late. This conveyed that this information is, and has been of great support to improving their performance.

\section{Productivity and customer service measures}

Questions were aimed at establishing what the interviewees viewed as important measures of good customer service and productivity and how this information is used to improve productivity and customer service.

Almost all the management interviewees responded by referring to the current measures of customer service and productivity, with an exception of L1, whose interest in customer service revolved around service quality. He immediately pointed out that the challenge with measuring service is around ensuring systematic and consistent measurement of quality. The measures mostly quoted by the interviewees include 'first time resolution', 'speed of answer', 'abandon rates', 'call audits', and 'customer satisfaction'. The group services manager (L2) did, however, caution that something like customer satisfaction is also hard to determine because of low survey response rates. This is confirmed by the Vocal Laboratories internet article which reports customer survey response rates at less than $1 \%$. The level of knowledge in the product and service offerings was also noted as what makes customer service outstanding.

It was interesting to note that the first response from the agents on this question was also 'first time resolution'. This is consistent with research as first time resolution is agreed to be the most important customer service measure. One agent also specifically mentioned good customer service goes hand in hand with the right tools for the job which is the right information. For him, without relevant information, he has no knowledge and thus no confidence in his products and services, thus validating the views of management. Supporting this view, Marr and Neely (2004:7) report that researchers from the Netherlands have found that customers expect a level of 'self-efficacy' (among other traits), which is translated to a belief that agents are competent in their duties.

On productivity, measures such as 'minimum amount of handle time' came out prominently for management. Other measures include 'income collected per agent', 'income collected per hour', 
and 'PTP rate'. For the services department, however, L2 indicated that productivity measures do not matter as much as customer service, given the priorities of that department. L2 further argued that it is imprudent to put a number on customer service. For his department, $75 \%$ of the calls must be answered within 20 seconds, $75 \%$ of the time. The global benchmark on this, according to IFC's benchmarking report, is at $80 \%$ of calls answered within 20 seconds. Marr and Neely (2004:5) argue a similar point, relating that quantitative statistics that measure productivity have largely been favoured over employee characteristics that create value for companies and their customers.

The agent's response to productivity was different and this was made obvious by their priorities and goals. Their measure of productivity included reaching their daily targets of PTP, sales, and the number of multimedia statements (MMS) sent (the agents are goaled on how many customers they convince to take up MMS or email for statements instead of normal post). All agents agreed to these measures, however, their responses were varied on whether they were seeing an improvement in achieving these goals since the implementation of the CC project.

\section{Challenges and opportunities}

Information dissemination and communications were disclosed as major challenges still plaguing the call centre for lower level managers and agents. A tight-fisted approach on certain relevant information was stated as hampering decision making and productivity at these lower levels. The agents described cases where a customer will call querying a status on their account that they do not have access to, resulting in the customer waiting on the call while the information is sought, and thus increasing the call duration. An opportunity for the agents in this regards was listed as disseminating information via the Edcon intranet. Access to relevant information will enable them to perform their tasks in the best way and increase their individual productivity, they stated.

Interestingly, skills-based routing became a follow-up question in the interviews with the management of the call centre. There were conflicting views on the usefulness of this from the different managers. Where L1 felt that this is one of the technologies they could certainly look at, L2 preferred multiskilling as an approach.

Communication, particularly in relation to the dissemination of information, emerged as a common thread among agents as one of the major challenges from these interviews. It was interesting to note that L1, being the executive in the call centre, did not believe communications to be a challenge though. This may allude to disconnects and communication breakdowns between the top level management and the agents on what is sufficient and relevant communication.

\section{Discussion}

Customer service is one of the pillars of the Edcon's CFS and as a result, major efforts are constantly put in place to ensure its improvement. Even though there are standard indicators of good customer service, such as first time resolution, it transpired from the interviews that measuring customer service is challenging. This is because good customer service may be subjective and it may depend on one brilliant service from one call or one appalling service from another call. What is clear from the interview with L1 is that quality is an imperative for his operation. As referenced in Marr and Neely (2004:8), the benefits of quality in customer service will improve the ability to attract new customers and retain current customers. It is thus apparent why this will rank higher in L1's view. The implementation of WFM in the collections department showed a dramatic improvement in adherence to schedule, bringing this measure in line with global benchmarks and thereby improving one of the measures of customer service.

The Edcon CFS is not unlike many call centres as some of their productivity measures compare with those described in literature. Many of the measures for outbound collections agents are thus centred on the number and the value of income collected per agent as well as PTP rates. This cements the view that there is a divergence of responsibilities and focus for call centre managers who have to intricately balance customer service, with cost reduction and income generation (Robinson \& Morley 2006:3). Belfiore et al. (2012:10) and Du Preez (2008:10) aptly refer to this as the 'call centre management balancing act'.

It is understandable that there would be a difference in productivity priorities between management and agents. The agents' view pertained to their daily goals whereas management regarded productivity holistically. Another interesting distinction was the difference in approach towards productivity between the collections and the services departments. Again, this is understandable as the collections teams are incentivised on their productivity goals whereas the services teams are not. Notwithstanding, productivity has certainly improved since the implementation of the CC project as demonstrated in the projected statistics above.

The role that MI plays in a call centre environment is vital. Researchers such as Barzegar et al. (2012:191) indicate that MIS provides call centres the potential to improve their operations. This is recognised by the management of Edcon's CFS and through implementations of new MIS, they are expecting to get more information that they can use to improve their call centre. The performance of the departments, teams, and individuals, augmented by the implementation of new MIS in CRM and WFM, and the new information insights expected from this implementation, is touted to further improve customer service as it has productivity in the collections department.

In summary, the CFS previously collected appropriate, albeit insufficient, information in the measures of their call centre because of the absence of suitable MIS. This information was being used in the daily operations of the call centre and was imperative in decision making. The CC project, however, 
addressed the lack of new MI through the implementation of WFM, CRM, and the CMS integration. All indications are that the CFS is moving in the right direction concerning the ideas and strategies they are looking to implement in the near future, based on the efficiencies they have realised in collections. Although there are still areas of improvement in the use of MI, such as considering skills-based routing, the CFS will continue to optimise the use of MI from the MIS they have acquired. Continuing on the vein of improving the functions and the operations of the call centre and using the available MI successfully will surely lead to further improvements in productivity and in working towards delighting their customers continuously and consistently.

Suggested future study for consideration for Edcon would be the measurement of the return on investment (ROI) on the CC project. In their study, Belfiore et al. (2012:7) found that there is a correlation between a call centre technology upgrade and improvement in performance, and that ROI is usually realised within a year or two of implementation. However, these researchers' study only focused on 143 call centres and they report this is still insufficient representation.

\section{Conclusion}

Increasing competitiveness is at the core of many profit companies. For a call centre, improving competitiveness translates to an increase in the number of calls that can be serviced in a time period, without sacrificing the quality of service to the customer. Call centres have been a subject of study for many researchers since the phenomenon of serving customers over the telephone became popular. The interest in call centres has primarily focused on the profiles and the performance of call centre agents, and what could be measured in a call centre to make it efficient. There have also been arguments and counter arguments, as seen in Marr and Neely's (2004) research report for Fujitsu, on what the appropriate measures should be.

This article, considered a different area that is an important aspect in improving the performance of a call centre, which is MI. The article reasoned that through effective use of MI, Edcon's CFS has been able to see an improvement in the existing productivity measures in their collections division. The effective use of MI was shown to be an important aspect in the decision making process and in actually influencing the improvements in productivity and customer service.

The research showed limitations on the part of Edcon in leveraging some of the important MI available such as customer insights and skills-based routing. Despite these limitations, the findings from the semi-structured, in-depth interviews showed that there is considerable appetite on the part of the CFS executive in finding the best solutions to maintain the call centre profitability. The implementation and availability of newly acquired MIS included in the implementation of the CC project will support this endeavour. Considerations for future research could therefore include exploring the benefits of these new MIS and their contribution to the advancement of Edcon's CFS. The article further recommends an investigation on the ROI of the CC project as advocated by Belfiore et al. (2012:7).

In the words of Victor Kiam, the CEO of Remington 'information is a negotiator's greatest weapon' (Sudor 2009:94). MI should thus be a vital consideration for call centre operations and its management. Utilising strategies to optimise this information as opposed to simply reporting on the information is not only prudent on the part of the company, but it will also safeguard their competitiveness in the long-term.

\section{Acknowledgements Competing interests}

The authors declare that they have no financial or personal relationships which may have inappropriately influenced them in writing this article.

\section{Authors' contributions}

M.M. ${ }^{1}$ (University of Johannesburg) and M.M. ${ }^{2}$ (University of Johannesburg) contributed equally to the writing of this article.

\section{References}

Adeoti-Adekeye, W.B., 1997, 'The importance of management information systems', Library Review 46(5), 318-327.

Aksin, Z., Armony, M. \& Mehrotra, V., 2007, 'The modern call centre: A multidisciplinary perspective on operations management research', Production and Operations Management Society 16(6), 665-668.

Banks, D. \& Roodt, G., 2011, 'The Efficiency and quality dilemma: What drives South African call centre management performance indicators?', SA Journal of Human Resource Management 9(1), 1-17.

Barnett, G., 2006, 'The contact centre industry: Where we've been and where we're going next', viewed 29 April 2015, from http://www.tmcnet.com/callcenter/0606/cis-contact-center-technology-0606.htm

Barzegar, N., Araghieh, A. \& Asgarani, M., 2012, 'The role of management information systems (MIS) to increase productivity in the workforce (case study of Iran)', Journal of Educational and Management Studies 3(3), 191-194.

Belfiore, B.L., Chatterley, J. \& Petouhoff, N., 2012, 'The impact of technology on contact centre performance', viewed 29 April 2015, from http://www.cisco.com/c/dam/en/ us/products/collateral/customer-collaboration/unified-contact-center-enterprise/ technology_contact_center_performance_research_report.pdf

Brooke, C., 2002, 'Information systems at call centre', International Journal of Information Management 22(2002), 389-401.

Dimension Data, 2014, 'Global contact centre benchmarking, Top 5 series', viewed 29 April 2015, from http://www.dimensiondata.com/Global/Downloadable $\% 20$ Documents/Top \%205\%20Series\%20-\%205\%20Steps\%20to\%20Clearer\%20 Performance\%20Management $\% 20$ Information.pdf

DMG Consulting, 2011, 'Making WFM work: best practices and ROI model', viewed 29 April 2015, from http://www.neccf.org/whitepapers/Making_Workforce Management_Work.pdf

Du Preez, J.J., 2008, 'Call centre design, operation and optimisation - A structured and scientific based approach', Master's dissertation, University of Stellenbosch, Stellenbosch.

Edcon RFP, 2011, 'Request for proposal for a migration strategy for the contact centre infrastructure at the Regional Credit Offices as well as an enterprise wide unified communication strategy', viewed 29 April 2015, from http://intranet/default.aspx

Edwards, S., 2009, Best practice guide for customer service professionals, Customer 1st International, UK, viewed 29 April 2015, from http://www.customerserviceglobal. com/files/customer_service_1st_sample_bpgcsp_ebook.pdf

Giao, P.R., Borini, F.M. \& De Miranda Oliveira Jr., M., 2010, 'The influence of technology on the performance of Brazilian call centres', Journal of Information Systems and Technology Management 7(2), 335-352.

Gupta, A., McMahon, S., Jain, A. \& Kanagasabai, K., 2008, 'Redefining the mission for banks; call centres: Cut costs, grow sales or both?', viewed 29 April 2015, from http://www.booz.com/media/uploads/Redefining_Mission_for_Banks_Call_ Centers.pdf

Higson, C. \& Waltho, D., 2010, 'Valuing information as an asset', SAS White paper, viewed 29 April 2015, from http://www.eurim.org.uk/activities/ig/ InformationAsset.pdf 
Holman, D., Batt, R. \& Holtgrewe, U., 2007, 'The global call centre report: International perspectives on management and employment', viewed 29 April 2015, from perspectives on management
$\mathrm{http}: / /$ www.globalcallcentre.org

International Finance Corporation, 2015, 'Measuring call centre performance, Global best practices', viewed 29 April 2015, from http://www.ifc.org/wps/ wcm/connect/ifc_ext_design/ifc+search/search/searchresultlandingpage?cx $=009183910618791464029 \% 3 \mathrm{Aik} 2 \mathrm{jtg} \mathrm{cdpm}$ \& $\mathrm{cof}=$ FORID\%3A11\&ie=\&q=call+ centre

Knowlagent Productivity Plus, 2011, 'Knowledge surveys on contact centre productivity', viewed 29 April 2015, from http://info.knowlagent.com/fastfacts.html

Mahesh, S.N., 2010, 'A study on effectiveness of MIS in organised retail stores in Vijayawada (with reference to BIG BAZAR)', viewed 29 April 2015, from http:// www.scribd.com/doc/44758500/RETAIL-STORES-MIS-BY-S-MAHESHGUMMADIDURRU-9248528762-k-I-university\#

Marr, B. \& Neely, A., 2004, 'Managing and measuring for value: The case of call centre performance', Cranfield University School of Management, viewed 29 April 2015 from http://www.uk.fijutsi.com

McCrae, J., Stephen, J., Mehta, R. \& Guermellou, T., 2012, 'Improving decision making in Whitehall: Effective use of management information', viewed 29 April 2015 from http://www.instituteforgovernment.org.uk/sites/default/files/publications/ Improving\%20decision\%20making\%20in\%20Whitehall.pdf

OECD, n.d., 'Measuring productivity', viewed 29 April 2015, from http://www.oecd. org/std/productivity-stats/2352458.pdf

Prunty, M. \& Pritchard, A., 2006, 'White paper on: The customer focused contact centre', viewed 29 April 2015, from http://www-935.ibm.com/services/us/gbs/ bus/pdf/the-customer-focused-contact-center.pdf
Rademeyer, D., 2012, 'A benefits model for the call centre strategy', Master's dissertation, University of Johannesburg, Johannesburg.

Reynolds, P., 2010, 'Call centre metrics: Best practices in performance measurement and management to maximise quiltline efficiency and quality', viewed 29 April 2015, from http://cymcdn.com/sites/www.naquitline.org/resource/resmgr/ issue_papers/callcentermetricspaperbestpr.pdf

Robinson, G. \& Morley, C., 2006, 'Call centre management: responsibilities and performance', International Journal of Service Industry Management 17(3), 284-300.

Rowe, F., Marciniak, R. \& Clergeau, C., 2010, 'The contribution of information technology to call centre productivity', Journal of Information Technology and People 24(4), 336-361.

Sharp, D., 2003, 'Call Centre operation: Design, operation and maintenance', Elsevier, Amsterdam.

Shen, H. \& Huang, J.Z., 2008, 'Interday forecasting and intraday updating of call centre arrivals', Manufacturing and Service Operations Management 10(3), 391-410.

Stringham, R. \& Cotter, M., 2012 'Best practices for improving first-contact resolution in the contact centre', viewed 29 April 2015, from http://www.oracle.com

Sudor, G., 2009, International business, SAGE, London.

Vocal Laboratories, 2014, 'Improving survey response rates', viewed 29 April 2015 from http://www.vocalabs.com/newsletter/improving-survey-response-rates

Zins, C., 2007, 'Conceptual approaches for defining data, information and knowledge', Journal of the American Society for Information Science and Technology 58(4), 479-493. 